\title{
Study on Environmental and Economic Development in Guangdong Province
}

\author{
Man Zhang \\ Department of Economy, Jinan University, Guangzhou, China \\ Email:623769001@qq.com
}

How to cite this paper: Zhang, M. (2017) Study on Environmental and Economic Development in Guangdong Province. Open Journal of Social Sciences, 5, 40-49. https://doi.org/10.4236/jss.2017.52005

Received: January 6, 2017

Accepted: February 1, 2017

Published: February 4, 2017

Copyright $\odot 2017$ by author and Scientific Research Publishing Inc. This work is licensed under the Creative Commons Attribution International License (CC BY 4.0).

http://creativecommons.org/licenses/by/4.0/

\begin{abstract}
With the continuous economic and social development and progress, Guangdong Province, while maintaining rapid economic growth, environmental conditions are deteriorating. Therefore, it is of great significance to study the coordinated development of ecological environment and economy in Guangdong. While the Environmental Kuznets Curve is the curve describing the relationship between environmental pressure and income per capita, this paper briefly introduces the research background and significance of this topic and the status quo of domestic and foreign research, and then introduces the economic development and the status of environmental quality of Guangdong. Then, it uses the EKC model to analyze the relationship between economic growth and environmental pollution in Guangdong, and analyzes shape and position of the EKC of Guangdong. Finally, it provides some suggestions for the coordinated development of environment and economy in Guangdong.
\end{abstract}

\section{Keywords}

Economic Development, Environmental Protection, Environmental Kuznets Curve

\section{Introduction}

Since the reform and opening up, China's economy has been growing at a steady and high speed. In 2010, the total GDP ranked second in the world. The total GDP in 2014 exceeded 60 trillion yuan for the first time, and it is the first time it exceeded 10 trillion US dollars mark. However, with the rapid and steady growth of China's economy, it is necessary to pay attention to the environmental costs of China's economic growth. Guangdong, as the forefront of China's reform and opening up, has maintained a good momentum of rapid and stable economic development. However, it also formed a high pollution and high energy consump- 
tion industries and manufacturing industry-based industrial structure, inevitably brought pollution and destruction of the ecological environment, Guangdong's sustainable economic development is facing enormous challenges. From the industrial "three wastes" emissions and environmental pollution situation, the Guangdong unit output of major pollutants emissions over the national average. Environmental pollution is increasingly serious, and a variety of environmental problems is detrimental to Guangdong's economic sustainable development.

In the face of the hot debate on the relationship between environmental pressure and economic growth, how to promote the coordinated development of economic growth and environmental protection in Guangdong has become an urgent problem to be solved. Environmental Kuznets Curve is the curve to reveal the relationship between environmental conditions and economic development, in this paper referred to as EKC. This paper uses the EKC to analyze the current economic and environmental development of Guangdong, and finds out the changing trend of Guangdong's economic situation with the economic development and give some suggestions and enlightenments. This paper first summarizes the status quo of relevant research at home and abroad, and then describes the status of Guangdong's economic development and environmental quality, followed by EKC model for empirical analysis and proposed a number of policy recommendations for the results, and finally a simple summary.

\section{Literature Review}

\subsection{Foreign Research Status}

The famous American economist Kuznets in the study of the income gap between countries in the world found that in the process of economic development, the income gap with economic growth showed the trend of increasing first and then down, there is an inverted U-shaped relationship between the curves is called the Kuznets curve [1]. Grossman and Kruger found that most of the changes in pollutants and national income per capita trends also showed inverted U-shaped curve [2]. Subsequently, Panayotou associated this relationship with the Kuznets 1955 proposed by the Kuznets curve hypothesis is very similar, and further studies have proved that the inverted U-type curve for the per capita income and environmental quality level of the relationship, so defined the relationship as the Environmental Kuznets Curve hypothesis [3].

Since the EKC hypothesis has been put forward, foreign scholars verified the hypothesis from different angles. Selden and Song in 1994 found that emissions of pollutants $\mathrm{SO}_{2}, \mathrm{NO}_{x}$, SPMT, $\mathrm{CO}$ and GDP per capita showed an inverted U-type relationship [4]. The existence of EKC and use the empirical analysis to predict the range of inflection points [5]. The time-series data of per capita GDP and $\mathrm{CO}_{2}$ emissions during the period 1960-1999 in Austria were to be cubic "N" rather than inverted "U" relationship [6].

\subsection{Domestic Research Status}

Chinese scholars began to quantify the relationship between economic growth 
and environmental quality at the end of the 20th century, and some achievements have been achieved through the unremitting efforts of a large number of scholars [7].

There were obvious conic EKC features (similar to inverted "U") between urban waste growth and GDP per capita in Shanghai [8]. The fitting curve of GDP per capita and industrial wastewater discharge in Guangxi was in a U-type relationship, and the industrial waste and industrial emissions were inverted the left half of U-type [9]. There was a clear linear relationship between industrial wastewater discharge and GDP per capita in Jilin Province, the relationship between industrial emissions and GDP per capita was quadratic U-shape curve, industrial solid waste emissions and per capita GDP was the three times N-type curve [10]. There were significant EKC features between industrial wastewater and industrial waste gas emissions with GDP per capita in Jiangsu Province, the per capita industrial solid waste emissions and per capita GDP was increased phenomenon [11]. The relationship between industrial "three wastes" emissions and economic development in Zhejiang Province does not accord with the typical inverted " $U$ " characteristics [12].

Thus, there is a necessary link between economic growth and environmental quality, but due to differences in policy, economic and trade, and environmental awareness among different countries or regions, there is a difference relationship between the two, they does not necessarily show a typical inverted U-type relationship, there may be positive U-type or N-type relationship [13]. Therefore, the relationship between economic growth and environmental quality in specific areas must be studied in depth according to the actual situation, rather than the simple application of inverted U-type relationship.

\section{The Status of Economic Development and Environmental Quality of Guangdong}

\subsection{Economic Development of Guangdong}

Since the reform and opening up, the economic development of Guangdong has made great achievements. From 1986 to 2014, the GDP of Guangdong increased from 66.753 billion yuan to 6.77929 trillion yuan, and the GDP per capita increased from 1164 yuan to 63452 yuan. In addition, Guangdong is China's first total GDP exceeded 6 trillion yuan in the province, and GDP for several years ranked first in the country, the economy has maintained a steady high-speed growth, GDP per capita is more than 10,000 US dollars in 2013.

\subsection{Environmental Quality of Guangdong}

The sustained and rapid economic development in Guangdong, while inevitably have a greater pressure on the ecological environment, increasing industrial waste emissions, environmental pollution problems was prominent. In 2014, the total discharge of waste water in Guangdong reached 9.051 billion tons, up by $4.94 \%$ over the last year. The discharge of industrial wastewater was 1.756 billion tons, accounting for $19.40 \%$ of the total wastewater discharge. The industrial 
waste water pollution in the most serious, because the industrial waste water contains a lot of lead, sulfide, mercury and other toxic and hazardous substances, the destruction of the environment is very large. The province's sulfur dioxide industrial emissions was 297.93 billion cubic meters, air pollution is serious, especially in the economically more developed Pearl River Delta region. The province produces 56.6609 million tons of general industrial solid waste, the general utilization of solid waste 4893.04 million tons, the disposal of 6.355 million tons, storage capacity of 1.4995 million tons, dumping 18,900 tons of dumping. The pollution of solid wastes mainly comes from the discharge of industrial solid wastes, the improper use of industrial solid waste, the decomposition of harmful elements into the atmosphere and soil, and ultimately brings about greater pressure on the city and the surrounding environment.

\section{Empirical Analysis and Policy Suggestions}

\subsection{Indicators and Data}

This paper chooses the GDP per capita as the index to reflect the economic growth and economic level, using the relevant data of Guangdong from 1986 to 2014. Emissions of industrial exhaust, industrial wastewater discharge, sulfur dioxide emission and industrial solid waste generation were used as the pollutant emission indicators [14]. Due to the availability of data, this paper mainly selected the industrial wastewater discharge, industrial waste gas emissions and industrial solid waste generation as environmental quality indicators, the data of Guangdong from 1986 to 2014. Data are derived from the Guangdong Statistical Yearbook of the relevant year or the Guangdong Provincial Environmental Statistics Bulletin and the China Environment Yearbook.

\subsection{Model}

Based on the previous research experience, this paper chooses the cubic function model, that is, according to the EKC theory to establish the equation:

$$
Y=a+b X+c X^{2}+d X^{3}+e .
$$

where $Y$ is the environmental quality indicator "three wastes" emissions, $X$ is the economic growth target GDP per capita, $e$ is a random error term. Among them, the model parameters $b, c, d$ for reflecting the relationship between environmental quality status and economic development is of great significance [15]:

1) When $b \neq 0$ and $c=d=0$, there is a linear relationship between environmental condition and economic development.

2) When $b>0, c<0, d=0$, the relationship between environmental conditions and economic development is inverted U-type quadratic curve.

3) When $b<0, c>0, d=0$, the relationship between environmental condition and economic development is U-type quadratic curve.

4) When $b>0, c<0, d \neq 0$, the relationship between environmental condition and economic development is cubic curve.

5) When $b=c=d=0$, there is no relationship between environmental condi- 
tions and economic development.

\subsection{Regression and Fitting of Model}

Use the SPSS software to do curve fitting for the GDP per capita and industrial wastewater discharge, industrial waste gas emissions and industrial solid waste generation respectively, the fitting results prove that the cubic regression curve can better reflect the relationship between the emissions of industrial waste and the GDP per capita of Guangdong.

Regression results show that the fitting curve coefficients of GDP per capita of Guangdong with industrial waste gas emissions and industrial solid waste generation are both higher than 0.95 , the fitting degree is higher and the effect is well. The adjusted $\mathrm{R}^{2}$ value of industrial waste gas emissions is 0.974 , which means $97.4 \%$ of the industrial waste gas emissions can be explained by the GDP per capita. The adjusted $\mathrm{R}^{2}$ value of industrial solid waste generation is 0.96 , which means $96 \%$ of industrial solid waste can be explained by the GDP per capita. And the fitting effect of Guangdong's GDP per capita and industrial wastewater discharge is less than 0.648 , which means that only $64.8 \%$ of the industrial waste water discharge can be obtained from GDP per capita to explain, other factors such as national environmental policies, laws and regulations to a greater extent affected the industrial wastewater discharge.

From the three fitting curves, we can see that the relationship between the three environmental quality indicators and GDP per capita in Guangdong is not the traditional inverted U-type EKC, and the three curves of the shape are not the same.

As shown in Figure 1, the fitting curve of industrial wastewater discharge and GDP per capita in Guangdong show the cubic curve characteristic of positive U-type and inverted U-type. From 1986 to 1995, with the increase of GDP per capita, the discharge of industrial wastewater gradually decreased, and the descending speed was slow and the change trend was not significant. From 1996 onwards until 2001, industrial waste water emissions are at a low level. From 2001 onwards, industrial wastewater discharge increased rapidly with the increase of GDP per capita. Among them, the rate of industrial wastewater discharge increased with the growth of GDP per capita from 2005 to 2007 has reduced, and from 2007 to 2009, the GDP per capita still maintained a big growth rate, but the industrial wastewater discharge has started to decline with the growth of GDP per capita. In 2008, the GDP per capita reached 37,638 yuan, the industrial wastewater discharge was lower than the level of 2005, after the year until 2013 are declining. Overall, since 1995, industrial wastewater discharge and GDP per capita showed strong inverted U-type characteristics, now on the right of inverted U-type.

Figure 2 shows that the fitting curve of industrial waste gas emissions and GDP per capita in Guangdong is characterized by weak "N" curve. Between 1986 and 1995, industrial waste gas emissions were slowly increasing with GDP per capita, and industrial emissions were at a low level during this period. In 1996, 


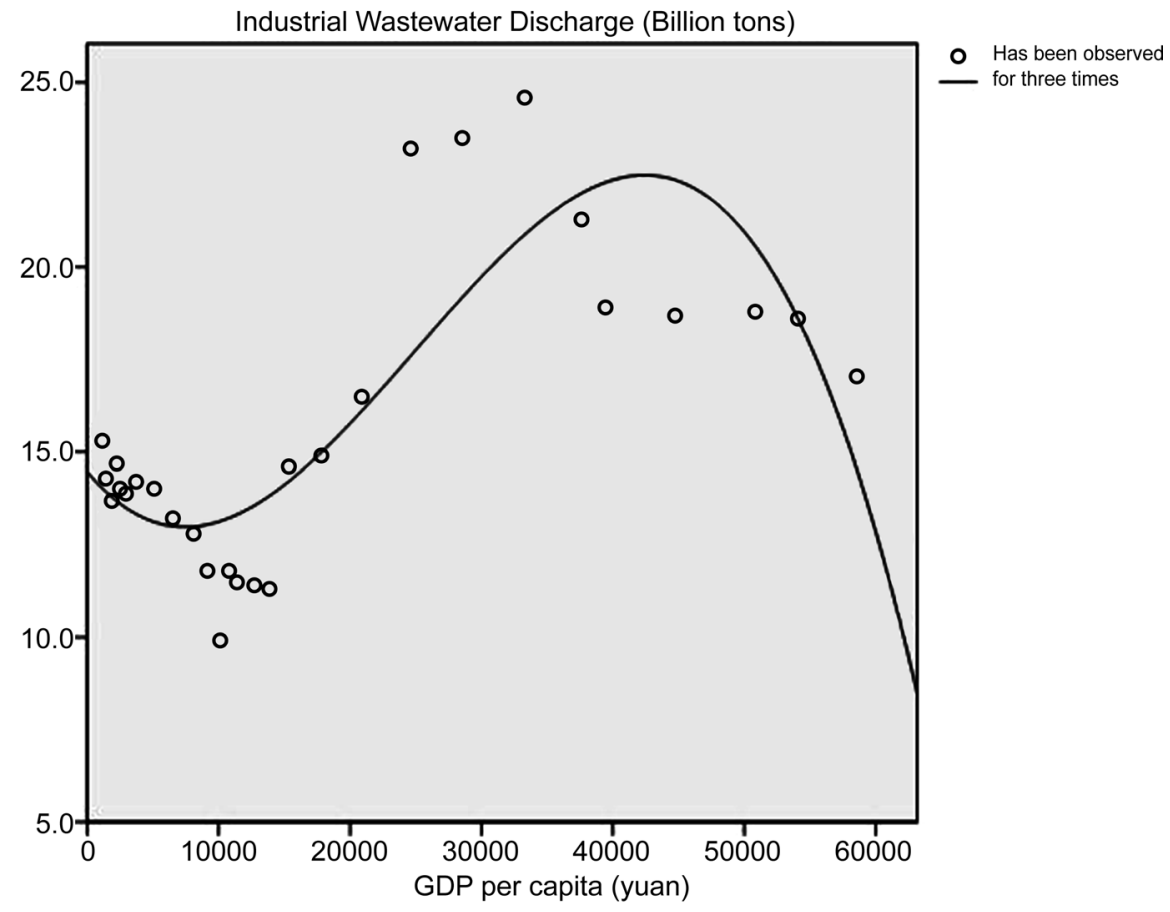

Figure 1. Fitting curve of industrial wastewater discharge and GDP per capita.

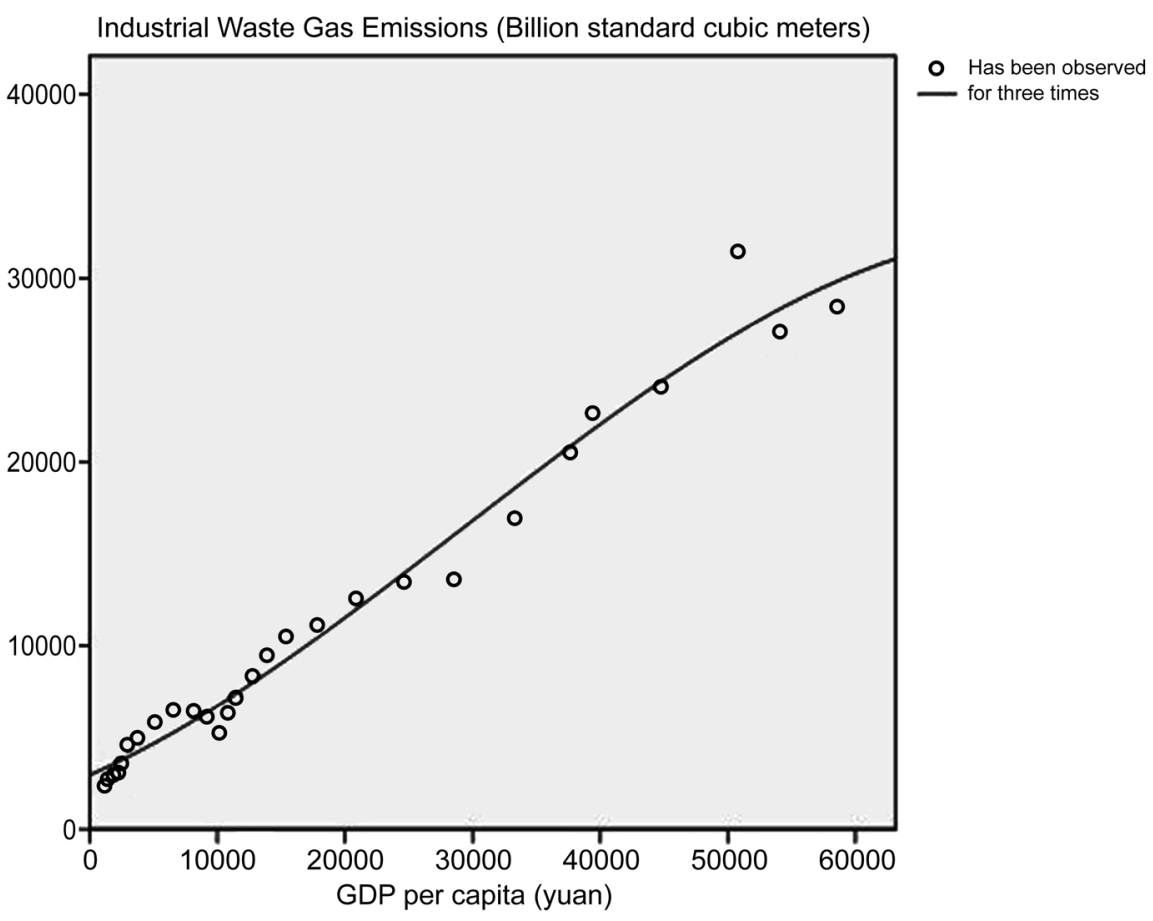

Figure 2. Fitting curve of industrial waste gas emissions and GDP per capita.

GDP per capita reached 9139 yuan when the industrial emissions reaching a turning point, that is, in 1996 there was a short decline. But then, industrial emissions began to rise rapidly, from 1996 to 2011 has been in the growth period, and growth rapid in the middle few years. 2012 also showed a brief downward trend, and then began to increase in 2013. At present, the relationship be- 
tween industrial emissions and GDP per capita is close to the right half of the U-type EKC and is expected to continue its growth trend after 2014.

It can be seen from Figure 3 that the fitting curves of industrial solid waste production and GDP per capita in Guangdong show the characteristics of three "N" curve of positive U-type and inverted U-type. The amount of solid waste generated from 1986 to 2000 is at a low level, but in 1986 and 1999 the level is relatively high. It can be found that the turning point of U-type curve reached when the GDP per capita reached 9139 yuan, that is, reached a turning point in 1996. Since then, solid waste production began to increase gradually, and began to rise rapidly in 2001, inverted " $U$ " curve are still in the left half of the rise until 2012, while the solid waste production in 2013 has a slight decline, but it is uncertain whether a temporary drop or inverted U-shaped curve has reached the turning point, so it is not known whether the turning point of inverted U-shaped curve appears.

\subsection{Policy Suggestions}

In order to achieve the simultaneous improvement of environmental quality and economic growth in Guangdong, this paper proposes the following suggestions:

1) In recent years, Guangdong has developed and revised many local laws and regulations on environmental protection. Legislation is the foundation, law enforcement is the guarantee, thus, law enforcement efforts also need to strengthen, the basic work of environmental quality prevention and control need to consolidate [16]. While gradually improving relevant laws and regulations on environmental protection and gradually achieving fair law enforcement, efforts should be made to intensify environmental protection and management of

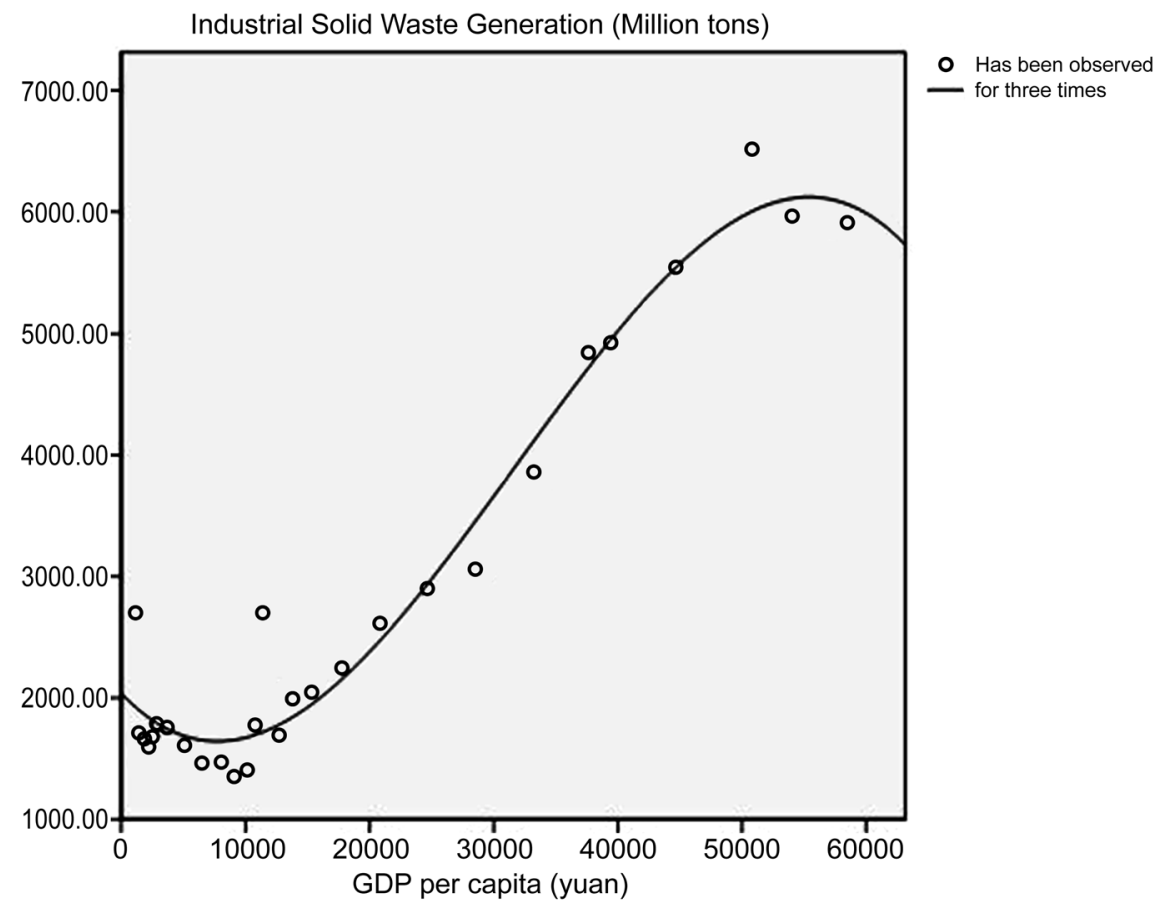

Figure 3. Fitting curve of industrial solid waste generation and GDP per capita. 
industrial wastewater discharge, industrial emissions and industrial solid waste generation, and continuously strengthen the "three wastes" governance, it may eventually achieve the overall improvement of the ecological environment, to achieve economic development and environmental quality simultaneously upgrade.

2) On the basis of strengthening the enforcement of legislation, it is also necessary to continuously strengthen the education and publicity of environmental protection related knowledge, through publicity and education, public participation and other means, through radio, television, newspapers and other media means strong publicity, To protect the ecological environment, promote the development concept, production concept, the consumption concept to the environment-friendly direction of transformation, thereby shortening our stay in the environment and economic dilemma of time, and ultimately the establishment of government-led, social, business, public participation in the pattern of environmental protection [17].

3) Guangdong's current industrial structure will still bring greater pressure on the ecological environment, therefore, industrial restructuring and industrial restructuring urgent need to accelerate. In order to take the initiative to adapt to the new normal economic development, Guangdong should further adjust the industrial structure, accelerate the transformation and upgrading of industry, and promote the integration of information technology and industrialization, and strive to enhance the quality and efficiency of economic development. In the future, Guangdong should accelerate the promotion of tertiary industry in the proportion of the whole industry, and further optimize the secondary industry, focusing on the development of high-tech industries with low-energy and lowemission, reduce the amount of pollution generated through technological innovation and upgrading.

\section{Conclusions}

Based on the actuality of environmental quality and economic development in Guangdong Province, this paper studies the relationship between environmental quality index and GDP per capita based on the data of Guangdong from 1986 to 2014 and analyzes the environmental Kuznets in Guangdong. After research and analysis, the conclusions of this paper are:

1) Rapid economic growth in Guangdong has led to a deterioration in environmental quality. Only the discharge of industrial wastewater is decreasing with the growth of GDP per capita, and the EKC is on the right side of the inverted " $U$ ". While industrial waste gas emissions and industrial solid waste generation still increased as GDP per capita increased, but the upward trend slowed down. It is expected that after several years of treatment, industrial solid waste production will gradually decline, because in 2013 it has begun to decline. Grasping the shape of EKC is helpful for us to know the present situation of environmental quality and provide the basis for the future development of environment.

2) Based on the research of Guangdong's EKC, some simple suggestions are 
put forward. It should strengthen the legislative and law enforcement work, environmental management, industrial restructuring and environmental awareness to promote the coordination of environmental and economic development proposals.

Many obvious shortcomings in this paper are needed to be studied and solved in the future work practice.

\section{References}

[1] Kuznets, S. (1955) Economic Growth and Income Inequality. American Economic Review, 45, 1-28. http://955.cc/xV2zw

[2] Grossman, G.M. and Krueger, A.B. (1992) Environmental Impacts of a North American Free Trade Agreement. Social Science Electronic Publishing, 8, 223-250. http://955.cc/xV35k

[3] Panayotou, T. (1993) Empirical Tests and Policy Analysis of Environmental Degradation at Different Stages of Economic Development. Working Paper, Technology and Employment Programme, International Labor Office, Geneva.

[4] Selden, T.M. and Song, D. (1995) Neoclassical Growth, the J Curve for Abatement, and the Inverted U Curve for Pollution. Journal of Environmental Economics \& Management, 29, 162-168. http://955.cc/xV6yW

https://doi.org/10.1006/jeem.1995.1038

[5] Hilton, F.G.H. and Levinson, A. (1998) Factoring the Environmental Kuznets Curve: Evidence from Automotive Lead Emissions. Journal of Environmental Economics and Management, 35, 126-141. http://955.cc/xV7KR https://doi.org/10.1006/jeem.1998.1023

[6] Klagenfurt, D.U., Friedl, B., Getzner, M., and Klagenfurt, U. (2003) Environment and Growth in a Small Open Economy: An EKC Case-Study for Austrian $\mathrm{CO}_{2}$ Emissions. Discussion Paper, Klagenfurt University, Klagenfurt. http://955.cc/xV2aM

[7] Zhang, Z.M., He, G.J. and Xiao, R.B. (2007) Land Surface Temperature Retrieval Based on MODIS and TM Data. Journal of Image and Graphics of China, 12, 366370. http://955.cc/xV9Cj

[8] Yang, K., Ye, M. and Xu, Q.X. (2003) Study on the Environmental Kuznets Characteristics of Waste Growth in Urban of Shanghai. Geographical Research, 22, 60-66. http://955.cc/xVA3r

[9] Xiao, Y., Wang, J.Y., Hu, X.T. and Li, Y.H. (2006) Study on Environmental Kuznets Curve in Guangxi. Journal of Northwest Forestry University, 21, 9-12. http://955.cc/xVBxi

[10] Su, W. and Liu, J.S. (2007) Study on the Relationship between Economic Growth and Environmental Pollution in Jilin Province. Journal of Arid Land Resources and Environment, 21, 37-41. http://955.cc/xVCbS

[11] Chen, C.H. and Lu, Z.N. (2008) An Empirical Analysis of Kuznets Curve on the Relationship between Economic Growth and Environmental Pollution in Jiangsu Province. Statistics and Decision Making, 13, 109-110. http://955.cc/xVCt7

[12] Yang, L.X. (2010) An Empirical Study on the Relationship between Economic Growth and Environmental Quality Evolution in Zhejiang Province. Geography and Geo-Information Science, 26, 78-80. http://955.cc/xVCKU

[13] Wang, R.L. and Chen, Y.J. (2005) Analysis of Kuznets Curve's Characteristics and Causes of "Three Wastes" Emission in China by Gray Correlative Degree Analysis. 
China's Population, Resources and Environment, 15, 42-47. http://955.cc/xVDpU

[14] Qin, C.C. and Liu, S.L. (2012) Status Quo, Comparison and Revelation of Influencing Factors of Carbon Emission. Economic and Management Review, 3, 29-33. http://955.cc/xVDGh

[15] Wu, K.Y. and Chen, X.J. (2003) Research on the Relationship between Economic Growth and Environmental Pollution in Anhui. Journal of Environmental Sciences of Chongqing, 25, 9-11. http://955.cc/xVEaV

[16] Li, Y.S. (2015) An Empirical Study on the Impact of Environmental Quality on Economic Growth in Guangdong Province. Science and Technology Management Research, 35, 237-241. http://955.cc/xVE4B

[17] Li, H.M. and Bu, X.X. (2003) How to Achieve a Win-win between Environment and Economy-Reflections on Environmental Kuznets Curve. Journal of Nankai University, 1, 58-64. http://955.cc/xVEVP

Submit or recommend next manuscript to SCIRP and we will provide best service for you:

Accepting pre-submission inquiries through Email, Facebook, LinkedIn, Twitter, etc. A wide selection of journals (inclusive of 9 subjects, more than 200 journals)

Providing 24-hour high-quality service

User-friendly online submission system

Fair and swift peer-review system

Efficient typesetting and proofreading procedure

Display of the result of downloads and visits, as well as the number of cited articles

Maximum dissemination of your research work

Submit your manuscript at: http://papersubmission.scirp.org/

Or contact jss@scirp.org 